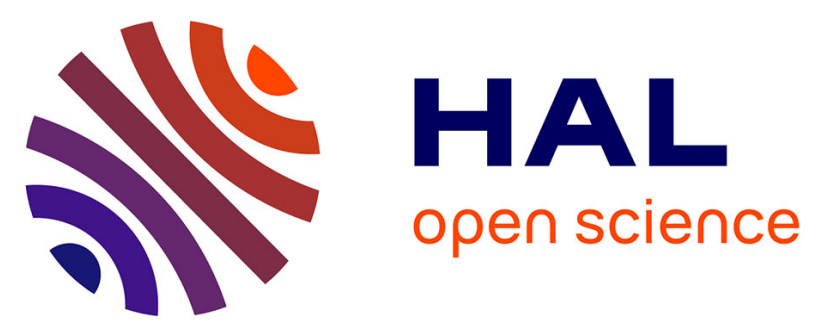

\title{
The RONSARD radars: internal calibration techniques using coherent and noise sources
}

\author{
B. Nutten, Danièle Hauser, F. Roux, Georges Scialom
}

\section{To cite this version:}

B. Nutten, Danièle Hauser, F. Roux, Georges Scialom. The RONSARD radars: internal calibration techniques using coherent and noise sources. [Research Report] Note technique CRPE n ${ }^{\circ} 70$, Centre de recherches en physique de l'environnement terrestre et planétaire (CRPE). 1979, 32 p. hal-02191392

\section{HAL Id: hal-02191392 \\ https://hal-lara.archives-ouvertes.fr/hal-02191392}

Submitted on 23 Jul 2019

HAL is a multi-disciplinary open access archive for the deposit and dissemination of scientific research documents, whether they are published or not. The documents may come from teaching and research institutions in France or abroad, or from public or private research centers.
L'archive ouverte pluridisciplinaire HAL, est destinée au dépôt et à la diffusion de documents scientifiques de niveau recherche, publiés ou non, émanant des établissements d'enseignement et de recherche français ou étrangers, des laboratoires publics ou privés. 


\section{NT/CRPE/70}

\section{THE RONSARD RADARS : INTERNAL CALIBRATION TECHNIQUES} USING COHERENT AND NOISE SOURCES

$$
\text { par }
$$

B. NUTTEN, D. HAUSER, F. ROUX, G. SCIALOM

\section{CRPE/ETE}

38-40 rue du Général Leclerc

92131 - ISSY-Tes-MOULINEAUX

Le directeur adjoint du CRPE

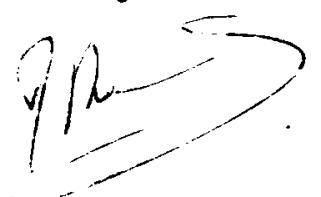

I. REVAH
L'Ingénieur en Chef chargé du département ETE $p_{i}$

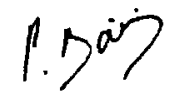

P. BAUER 
This paper describes the methods for calibrating each meteorological radar of the RONSARD system. The special procedures used have their origin in the complexity of the equipment.

The internal calibration of the receiver chain, which is the first step of the overall radar calibration, is described first.

The complex structure of the receiver is analysed and each element replaced by an equivalent circuit, yielding thus a reduced block diagram of the receiver chain. This diagram is then used to determine the receiver gain as a function of the receiver parameters. Special attention is given to the behavior of the receiver adapted filter (pre-integrator) and to that of the hard-wired Fourier transformer when processing various types of signal spectra.

Three measurements of the receiver gain are finally carried out using calibrated sources (coherent radio frequency source, $10600^{\circ} \mathrm{K}$ noise source, and internal radar noise). The results exhibit a correct stability of the radar constant obtained from independant measurements. The addition of quantization noise in the Fourier transformer is also analyzed and discussed. 
Radar systems used for the purpose of investigating the propagation of electromagnetic waves through precipitation must be carefully calibrated, since the relationships between reflectivity and characteristics of precipitation or radioelectric parameters are highly sensitive to variations in measured reflectivity [2].

The present paper outlines the problems encountered when calibrating the RONSARD meteorological radars. These complex radars require special procedures. After a brief review of the radar equation history, a generally accepted formulation is suggested (section II). Section III describes an equivalent diagram of the receiver and processor chain where each radar component is represented by its main characteristics (gain, attenuation, added noise temperature or non-linear behavior). An internal calibration of the radars using different kinds of calibrated sources, including the radar noise itself, is finally carried out for each of the possible Pulse Repetition Frequency modes.

The independent measurements of the internal radar constants are compared and discussed in section IV. 
RONSARD radars are single antenna pulsed Doppler systems designed for meteorological purposes. For such radars, the echo signal received in the feed horn from distributed scatterers is a function :

- of the overall scatterers cross section,

- of the antenna characteristics,

- of both the transmitted pulse and the propagation medium losses.

The so called "radar equation" connecting these elements has been widely described in the litterature during the past few years $[4,7,1]$. We assume, in the present study, the last formulation of the radar equation [1], including the resolution cell width correction $[3,5]$, and we try to infer the law relating the recorded data and the scattered power. In the case of RONSARD radars, due to their numerous modes of operation, the single "radar constant" of standard radars becomes a complex receiver equation. So we shall discriminate in the following between the radar equation (returned power versus target characteristics) and the receiver equation (power measurements versus returned power).

The well known equation established by Marshal1, Hitschfeld and Gunn [4] has later been modified in order to take into account more realistic conditions as shown in Equ (1) $[7,5]$.

$$
P_{R}=P_{T} \times \frac{G^{2} \lambda^{2} \theta^{2} h F}{1024(1 n 2) \pi^{2} r^{2}} \quad \sum \sigma_{i}
$$


where.$P_{R}$ and $P_{T}$ are the received and transmitted powers as measured at the feed horn imput,

- $r$ is the distance between the observed resolution cell and the radar,

- $h$ is the space width of the transmitted pulse,

- $\sum \sigma_{i}$ is the radar cross section of the target per unit volume,

- $G$ is the in-axis antenna gain,

- $\theta$ is the beam width in radians,

- $\lambda$ is the wave-length of the transmitted pulse,

- $F$ is the corrective factor introduced by Nathanson and Smith $[5,3]$ equal to 0.6 in adapted filter conditions.

Under the assumption of Rayleigh scatterers, the summation $\sum \sigma_{i}$ may be replaced by $\frac{\pi^{5}}{-\lambda^{4}}|K|^{2} Z$, where $z$ is the "reflectivity factor", only function of the drop size distribution of the scatterers in the observed volume $\left(|K|^{2}\right.$ is equal to 0.93 for water particles) :

$$
P_{R}=P_{T} \times \frac{\pi^{3} G^{2} \theta^{2} h|k|^{2}}{\lambda^{2} \times 1706(1 n 2)} \times \frac{Z}{r^{2}} .
$$

Actually, corrective factors must also be introduced in order to take into account absorption by atmospheric gases and hydrometeors. Eq. 2 being established under specific assumptions on the antenna characteristics (Gaussian beam shape) and receiver behavior (adapted filter conditions), its validity must be controlled by direct measurements such as soundings on calibrated targets. For this purpose, the receiver and the numerical chain responses as well as the transfer function accuracy have to be fully analyzed. This discussion, which is a preliminary task of the radar calibration, is undertaken in the following. 
A block diagram of RONSARD radars is presented in Fig. 1 a [6]. The RF stages of the receiver consist of a dual polarization system (orthomode, TR, limiter and polarization switch) and a two stages switchable parametric amplifier followed by a $6 \mathrm{~dB}$ steps adjustable attenuator. This amplifier and attenuator assembly is used for an Automatic Gain Control over a +30 to $-50 \mathrm{~dB}$ gain range.

The RF signal is then mixed with a local oscillator output. The obtained IF signal is processed by a Sensitivity Time Control (STC) system meant to counterbalance the effect of the $1 / r^{2}$ variation of the signal. After an additional IF gain, the IF signal is mixed with the outputs of a two phases If oscillator, thus yielding a complex "zero frequency" video signal. A couple of pre-integrators performs, on each component of the complex video, an integration which spatially defines the width of the range gates.

After analog to digital conversion, the digital processor comprises :

$i$ - an Amplitude and Phase Memory to correct the amplitude and phase variations of the transmitted pulse,

ii - a switchable high pass digital filter for ground clutter cancelling,

iii - an approximate Discrete Fourier Transformer followed by a power spectrum density computer.

An additional post-processor, operating on power spectrum densi- 
ties, computes in real time the first three moments $M_{0}, M_{1}$ and $M_{2}$ of the spectra thus allowing a high compression of the recorded data.

This complex structure obviously does not lend itself to an internal radar equation formulation. A formalization attempt has been undertaken in order to replace each receiver and processor component by an equivalent circuit characterized by its main features (gain or attenuation, added noise or non-linear parameters). This is summarized in table 1 and yields an equivalent block diagram of the radar (Fig. 16). Fig. 2 outlines a reduced block diagram of the whole receiver chain using a minimum number of subsystems. This will be used for the overall effective noise temperature determination and for the receiver constant calculation, both as functions of the AGC position.

III - 1 - Receiver effective noise temperature

All cascaded elements of the simplified diagrams in Fig. 2 theoretically take part in the radar effective noise temperature. However, the large gain of the IF amplifiers ensures that signal-to-noise ratio is not reduced beyond the RF mixer. Fig. 2 also show the only active components affecting the noise temperature; this one is readily deduced from the standard equation allowing to compute the noise temperature for cascaded circuits [9]. The equation giving the overall noise temperature, as estimated at the feed horn input, is then :

$$
\theta=\theta_{A N T}+\left(L_{R}^{-1}-1\right) \theta_{0}+L_{R}^{-1} \theta_{P A}+\frac{1-L_{R F}}{L_{R} L_{R F} G_{P A}} \theta_{0}+\frac{1}{L_{R} L_{R F} G_{P A}}{ }^{\theta_{M}}
$$

where $\theta_{0}$ is the standard external temperature value $\left(\theta_{0}=290^{\circ} \mathrm{K}\right), \theta_{\text {ANT }}$ the antenna noise temperature and $L_{R F}$ the overall RF gain of the RF chain following the parametric amplifier (i.e $L_{R F}=L_{A G C} \cdot L_{C A L} \cdot L_{I N S}$ ). 
Taking advantage of $L_{R F}$ low value $(<0.1$ for both radars), the formula is slightly simplified :

$$
\theta=\theta_{A N T}+\left(L_{R}^{-1}-1\right) \theta_{0}+L_{R}^{-1} \theta_{P A}+\frac{1}{L_{R} L_{R F} G_{P A}}\left(\theta_{0}+\theta_{M}\right)
$$

and shows the variation of the effective noise temperature at the input of the feed horn as a function of the AGC attenuation. This is illustrated in Fig. 3 deduced from measurements on one of the two radars. It is found that this noise temperature is exponentialiy increasing with respect to the AGC attenuation. The corresponding noise figure $F=1+\frac{\theta}{\theta_{0}}$ displayed in Fig. 3 has simultaneously a linear variation for AGC attenuations greater than $12 \mathrm{~dB}$, providing a constant signal-to-noise ratio close to $20 \mathrm{~dB}$.

\section{III - 2 - Receiver constant calibration}

The self calibrating capabilities of RONSARD radar have been described in a companion paper [6] ; they offer the possibility of using the internal, temperature regulated, $\mathrm{RF}$ source as a reference sinusoidal signal. Similarly one might use the internal radar noise, assuming it has been previously calibrated.

However one should take into account the different nature of these signals when interpreting the pre-integrators response. Assuming that $B$ is the bandwith of the receiver before the pre-integration, and $T$ the time duration of the pre-integration defining the width of the range gate, it can be shown (appendix $n^{\circ} 1$ ) that the power gain of the pre-integrators is :

$$
\begin{aligned}
& \cdot C^{2} T^{2} \text { in case of coherent signals, } \\
& \text {. } C^{2} T / B \text { in case of gaussian white noises, }
\end{aligned}
$$

where $C$ is a gain constant, which in RONSARD receivers, is adjusted to a 
value close to $1 / T$ depending upon the choosen range gate width. Thus the pre-integrator gain is 1 for coherent signals, and close to $\frac{1}{B T}$ when processing white noises.

In addition, the hard-wired Fourier processor has a different response to coherent or white noise type signals, and its behavior also changes in presence of meteorological echoes :

$i$ - for coherent signals, the effect of spectrum line cancelling under a $-12 \mathrm{~dB}$ threshold $[6]$ is equivalent to a gain reduction and an additional noise,

ii - for white noise, the previous effect is increased by the quantization noise due to equidistribution of spectral lines,

iii - meteorological signals have both deficiencies. In addition, the time variation of amplitude, which is related to spectrum broadening, is the cause of random clamping, globally reducing the gain.

The whole Fourier processor comprising the Approximate Discrete Fourier Transform, the Power Spectrum Density computer, and the $1^{\text {rst }}$ moment computer is too complex for a complete analysis. A whole investigation of the device has been done by the mean of computer simulation. Appendix 2 summarizes both the computation algorithms and the results.

In the following calibrations, only recorded time series are used, taking advantage of their great variation range ; the temporarily ignored Fourier processor parameters are re-introduced in last overall radar equation.

III - 3 - Calibration with the internal sinusoidal RF source

The calibrated source is injected through a $40 \mathrm{~dB}$ coupler at the parametric amplifier input; a signal-to-noise ratio greater than $12 \mathrm{~dB}$ ensures 
that noise sources can be neglected. Refering to Fig. 1b, the receiver equation is simply :

$$
M_{0}=\left(L_{R F} G_{I F} G_{P A}\right) P_{S}
$$

where.$M_{0}$ is the ideal $1^{\text {rst }}$ moment of the PSD computed without quantization
noise,

- $P_{S}$ is the injected source power.

III - 4 - Calibration with the radar noise

The unavoidable radar noise, previously calibrated, has naturally a Gaussian probability density and a uniform spectrum over the whole parametric amplifier bandwidth. Assuming that $B$ is the receiver bandwith before pre-integration, the part of the noise power at the input of the feed horn contributing to the noise power measurement has a bandwidth $B$. This noise power $P_{N}$ is :

$$
P_{N}=k B \text {, }
$$

where.$k$ is the Boltzman constant ( $\left.k=1.3810^{-23} \mathrm{~J} /{ }^{\circ} \mathrm{K}\right)$

- $\theta$ is the previously computed effective noise temperature at the feed horn input $\left({ }^{\circ} \mathrm{K}\right)$.

The internal radar equation is then :

$$
M_{0}=\frac{1}{B T} L_{R F} G_{I F} G_{P A} P_{N}
$$

(6)

$$
M_{0}=L_{R F} G_{I F} G_{P A} \frac{k \theta}{T}
$$

which is not dependent upon the radar bandwidth. 
Nevertheless, $\theta$ as well as $G_{P A}$ and $L_{R F}$ are functions of the AGC position depending upon the short-term time varying noise intensity. So, the recorded data have to be interpreted according to the AGC attenuation.

III - 5 - Calibration with a reference white noise RF source

Both radar calibrations using the sinusoidal RF source and the radar noise are operated without mechanical disassembling and are easily incorporated as calibration sequences during scientific observational campaigns.

Nevertheless, additional measurements are easily obtained by coupling an external $10600^{\circ} \mathrm{K}$ white-noise RF source at the parametric amplifier input. The equation (6) is still applicable assuming that the $\theta_{N}$ noise temperature of the RF source is accounted for in the $\theta$ computation. The new radar temperature equation is derived from (4) where antenna temperature and RF losses are omitted and the parametric amplifier noise temperature increased with $\theta_{N}$ :

$$
\theta=L_{R}^{-1}\left(\theta_{P A}+\theta_{N}\right)+\frac{1}{L_{R} L_{R F} G_{P A}}\left(\theta_{0}+\theta_{M}\right)
$$


Several experiments have been performed, according to the previously mentioned methodology, on the two radars. Each radar is successively operated in the two possible transmitter frequency modes (5600 and $5630 \mathrm{MHz}$ ) and in the two receiver polarizations. Results for one radar (operated at $5630 \mathrm{MHz}$ / Direct polarization) are presented in table 2, abc where the receiver constants obtained by the way of independent measurements using sine wave or noise calibrated sources can be compared for each pulse repetition frequency.

In case of measurements using the sinusoidal RF source, the power fed to the input of the parametric amplifier is equal to $-79.2 \mathrm{dBm}$ for all PRF's. The estimated receiver constant is simply the difference between the measured first moment $M_{0}$, expressed in $d B$ and the input power.

The radar noise, estimated from Equ. 4, is only mentionned to ensurethat the signal-to-noise ratio is great enough for a valid measurement. It should be noticed that the radar noise decreases by $3 \mathrm{~dB}$ going from the 50 meters to 100 meters range gate width (tables $2 \mathrm{a}$ and $\mathrm{b}$ ) since the AGC position equals the same $30 \mathrm{~dB}$ value. On the contrary the comparison of tables $2 \mathrm{~b}$ and $\mathrm{c}$ exhibit a $9 \mathrm{~dB}$ interval between the estimated radar noises : this is due to the different $A G C$ attenuations ( $30 \mathrm{~dB}$ and $24 \mathrm{~dB}$ ).

In case of measurements using the internal radar noise, the receiver constant is the difference between the first moment in $d B$ and the radar noise computed from Equ. 4. In several cases, the AGC has switched once or twice on peaks in the noise intensity, providing further measurements of the receiver constant obtained from different noise powers. 
Measurements of the receiver constant from the $10600^{\circ} \mathrm{K}$ noise source are similar except that the equation for computing the noise power is Equ. 7, including the noise temperature of the RF source.

The receiver constants measured for each of the three possible range gate widths are found within a $0.6 \mathrm{~dB}$ interval. This is the theoretical limit in RONSARD radars accuracy since, if we assume a correct radar equation, the average reflectivity factor that can be obtained from recorded time series has an absolute accuracy limited to $\pm 0.3 \mathrm{~dB}$. However, the obtained receiver constants do not include the mean attenuation and quantization noise due to the approximate DFT. It has been shown in appendix 2 that, when processing the spectra first moment $M_{0}$, the additional errors involve a reduced accuracy of the mean reflectivity factor estimate which amonts to the order of $\pm 0.5 \mathrm{~dB}$. In addition, this bias is contaminated by a $1.8 \mathrm{~dB}$ additional noise due to quantization effects in the Fourier processing.

Finally, the receiver gain may be obtained with a $\pm .3 \mathrm{~dB}$ accuracy when recording time series while a lower $\pm .5 \mathrm{~dB}$ accuracy is implied by the hard wired Fourier Transform processor. The quantization noise, neglictible in case of time series $(<.1 \mathrm{~dB})$ is significant when processing first moments, though it does not affect the mean estimate of the reflectivity factor.

The present work is the first step of the global RONSARD calibration program. The overa $11 \pm .3 \mathrm{~dB}$ deviation between the mean internal radar constants obtained from independant measurements, characterizes the upper limits of accuracy for future measurements. They will consist of a global examination of the external radar equation including :

- active soundings on a calibrated sphere,

- comparison of radar data to disdrometer and rain-gauges,

- passive observation of the available radio sources (sun and moon).

These operations are scheduled for 1979, and will be reported in a future paper. 


\section{APPENDIX 1}

PRE-INTEGRATORS RESPONSE TO A COHERENT SIGNAL AND A WHITE NOISE

Assuming $e(t)$ and $s(t)$ are the complex signals at the input and the output of the pre-integrators, $s$ is given by the equation:

$$
s\left(t_{0}\right)=c \int_{t_{0}-T / 2}^{t_{0}+T / 2} e(t) d t
$$

where $t_{0}$ is the time delay between transmitted pulse and the received echo, and $T$ is the duration of the range gate. $C$ is the integrator constant.

\section{Sinusoi]dal_signa]}

When $e(t)$ is a sinusoidal signal $A e^{j \omega_{0} t}$, the pre-integrators response is simply derived from (10):

$$
s\left(t_{0}\right)=c T e\left(t_{0}\right) \cdot \frac{\sin \left(\omega_{0} T / 2\right)}{\omega_{0} T / 2} \text {. }
$$

In case of RONSARD radars, $\omega_{0} T / 2$ is smaller than 0.13 and the 1 ast corrective factor can be neglected. The pre-integrators gain is therefore of the order of $C^{2} T^{2}$. 


\section{Gausss_iàn whit_e no noise}

Equation (10) can be interpreted as a convolution of the input signal $e(t)$ with a rectangular shaped function $p(t)$ defined as follows :

$$
\left\{\begin{array}{lll}
p(t)=1 & \text { for } & -\frac{T}{2}<t \leqslant \frac{T}{2} \\
p(t)=0 & \text { for } & t \leqslant-\frac{T}{2}, t>\frac{T}{2} .
\end{array}\right.
$$

Assuming that $E(\nu), S(\nu)$ and $P(\nu)$ are the Fourier transforms of $e, s$ and $p$, the convalution becomes:

$$
s(t)=\int_{-\infty}^{+\infty} e(u) p(t-u) d u \Longrightarrow s(v)=E(v) \times P(v) .
$$

Then the power $\sigma_{\text {out }}^{2}$ of the output noise is given by the expression :

$$
\sigma_{\text {out }}^{2}=\int_{-\infty}^{+\infty} s(\nu) S^{*}(\nu) d \nu=\int_{-\infty}^{+\infty} E(\nu) E^{*}(\nu) P(\nu)^{2} d \nu .
$$

The spectrum width of the input noise is 1 imited by the receiver to a bandwidth $B$. We assume, for this spectrum, a rectangular shape so that, $\sigma_{\text {in }}^{2}$ being the input noise power, the input noise spectrum is defined by equ. 14 :

$$
\left\{\begin{array}{l}
E(\nu) \cdot E(\nu)^{*}=\frac{\sigma^{2} \text { in }}{B} \text { for }-B / 2<\nu \leqslant B / 2 \\
E(\nu) \cdot E(\nu)^{*}=0 \text { for } \nu \leqslant-B / 2 \text { or } \nu>B / 2 .
\end{array}\right.
$$

In addition, $P(\nu)$ is easily deduced from $P(t)$ :

$$
P(\nu)=T \cdot \frac{\sin (\pi \nu T)}{\pi \nu T}
$$


Then the output power is derived from equation (13) :

$$
\begin{aligned}
& \sigma_{\text {out }}^{2}=\frac{\sigma^{2}{ }_{\text {in }}}{B} \cdot T^{2} \cdot \int_{-B / 2}^{B / 2}\left[\frac{\sin (\pi v T)}{\pi v T}\right]^{2} d v \\
& \sigma_{\text {out }}^{2}=\frac{T}{B} \cdot \sigma_{\text {in }}^{2} \cdot K
\end{aligned}
$$

where $K$ is a corrective factor given by the following expression :

$$
K=\frac{2}{\pi} \int_{0}^{\frac{\pi B T}{2}}\left(\frac{\sin x}{x}\right)^{2} d x
$$

which rapidly converges to unity when $\pi B T / 2$ increases. The pre-integrators gain in case of Gaussian white-noise is thus taken to be T/B. 
A simulated signal with the same statistical properties as echoes from meteorological targets has been generated, according to the procedure described by Sirmans and Bumgartner [8].

64 complex $x_{i}+j y_{j}$ samples time series are processed in a simulated Approximate Direct Fourier Transformer (ADFT). The word length of the complex time series as well as truncation of sine and cosine tables are similar in the program and in the hard wired machine.

The Power Spectrum Densities computed from the complex spectra are then processed in a simulated post-processor performing :

1 - The research of the maximum amplitude $S_{M}$ among spectral 1 ines,

2 - The cancellation of the spectral lines below $S_{M} / 16$ (SM - $12 \mathrm{~dB}$ ),

3 - The PSD first moment computation, respecting the word length of the actual machine.

The input power of the whole Fourier processor (i.e. the power of the input time series) is :

$$
P_{i n}=\sum_{1}^{64}\left(x_{i}^{2}+y_{i}^{2}\right) \text {. }
$$


The resulting first moment $M_{0}$ of the PSD yields a measurement ot the output power $P_{\text {out }}$, taking a fitting factor into account.

The $P_{\text {out }} / P_{\text {in }}$ ratio is finally computed for each periodogram, and a mean $P_{\text {out }} / P_{\text {in }}$ value obtained from 300 time series. The same process is repeated for various mean input power values and spectrum widths.

Results of that simulation of RONSARD processors are summarized in Fig. 4 showing the processor loss $P_{\text {out }} / P_{i n}$ as a function of the normalized input power (input power refered to the maximum value). It is found that, for a fixed standard deviation of the PSD, the overall Fourier processor loss variations are included within $.9 \mathrm{~dB}$ interval. In addition, a suitable translation of curves $b$ to e leads to a correct fitting with curve a (with a $.4 \mathrm{~dB}$ maximum error in region II). Thus a corrective factor, function of the measured variance, can yield a mean loss estimate with a $\pm 0.5 \mathrm{~dB}$ accuracy. 


\section{REFERENCES}

[1] Battan, L.J., 1959, revised in 1973 : Radar observation of the atmosphere, University of Chicago press (Chicago and London).

[2] Crane, R.K., K.M. Glover, 1978 : Calibration of the Spandar radar at Wallops Island. Preprints of $18^{\text {th }}$ conf. on radar meteorology, Atlanta Ga Ame. Meteor. Soc., 276-280.

[3] Doviak, R.K., D. Zrnic, 1979 : Receiver bandwith effect on reflectivity and Doppler velocity estimates.

J. App 1. Meteor., 18, 69-76

[4] Marschall, J.S., W. Hitschfeld and K.L.S. Gunn, 1955, Advances in radar weather. Advances in geophysics, 2 : 1-56, New-York academic press.

[5] Nathanson, F.E. and P.L. Smith Jr, 1972 : A modified coefficient for the weather radar equation. Preprints of the $15^{\text {th }}$ Radar Meteor. Conf. Champaign-Urbana I1linois, 228-230.

[6] Nutten, B., P. Amayenc, M. Chong, D. Hauser, F. Roux and J. Testud : The Ronsard radars : a versatile $C$ banddual Doppler facility, submitted to IEEE Transaction in Geoscience Electronics - Special issue on Radio Meteor. Nov. 1979, Amer. Meteor. Soc.

[7] Probert-Jones, J.R., 1962 : The radar equation in meteorology, Quart. J. Roy. Meteor. Soc., 88, 485-495.

[8] Sirmans, D. and B. Bumgarner, 1975 : Numerica] comparison of five mean frequency estimators, J. Ap1. Meteor., 14, 991-1003.

[9] Skolnik, M.I., 1962 : Introduction to radar systems, Mc Graw-Hil1 Book company inc. 


\begin{tabular}{|c|c|c|c|}
\hline Radar component & Gain (3) & $\begin{array}{l}\text { Effective noise } \\
\text { Femperature }\left({ }^{\circ} \mathrm{K}\right)\end{array}$ & Remarks \\
\hline Transmitter losses & $\mathrm{L}_{\mathrm{T}}$ & & $\begin{array}{l}\text { Including RF guides and } \\
\text { circulator }\end{array}$ \\
\hline $\begin{array}{l}\text { Receiver losses before } \\
\text { parametric amplifier }\end{array}$ & $L_{R}$ & & $\begin{array}{l}\text { Including orthomode, circu- } \\
\text { lator, TR, polarization } \\
\text { switch and RF guides }\end{array}$ \\
\hline Parametric amplifier & $G_{P A}$ & $T_{P A}=120^{\circ} \mathrm{K}$ & $\begin{array}{l}30 \mathrm{~dB} \text { or }-2 \mathrm{~dB} \\
\text { Depending upon the } A G C \text { value }\end{array}$ \\
\hline Gain control attenuator & $\mathrm{L}_{A G C}$ & & $\begin{array}{l}0 \text { to } 48 \mathrm{~dB} \\
\text { Depending upon the } \mathrm{AGC} \text { value }\end{array}$ \\
\hline Gain calibrating attenuator & $L_{C A L} L_{R F}$ & & $\begin{array}{l}0-6 \mathrm{~dB} \text { computer controlled } \\
\text { attenuation }\end{array}$ \\
\hline $\begin{array}{l}\text { Overall RF residual inser- } \\
\text { tion losses }\end{array}$ & $\mathrm{L}_{\text {INS }}$ & & $\begin{array}{l}\text { Including residual losses of } \\
\text { gain control and gain cali- } \\
\text { brating attenuators }\end{array}$ \\
\hline $\begin{array}{l}\text { RF mixer/Pre-amplifier/ } \\
6 \mathrm{MHz} \text { low-pass filter }\end{array}$ & $\mathrm{G}_{\mathrm{IF}}(1)$ & $T_{M}=1200^{\circ} \mathrm{K}$ & \\
\hline $\mathrm{STC} / \mathrm{IF}$ attenuator & $L_{S T C}, G_{I F}(1)$ & & $\begin{array}{l}0-24 \mathrm{~dB} \text { continuously } \\
\text { variable attenuator }\end{array}$ \\
\hline $\begin{array}{l}\text { If amplifier, all IF inser- } \\
\text { tion losses and cable losses } \\
\text { IF mixers }\end{array}$ & $\mathrm{G}_{\mathrm{IE}}$ & & \\
\hline Pre-integrators & $G_{P I}$ & & $\begin{array}{l}\text { Function of the signal natu- } \\
\text { re (white noise, coherent } \\
\text { signal or mixed signal) }\end{array}$ \\
\hline Amplitude and phase memory & - & $\begin{array}{c}\text { Quantization (2) } \\
\text { noise }\end{array}$ & \\
\hline Fixed target cancellor & $G_{M T I}$ & $\begin{array}{l}\text { Quantization (2) } \\
\text { noise }\end{array}$ & $\begin{array}{l}\text { Function of two command } \\
\text { parameters (cut-off frequen- } \\
\text { cy and slope) }\end{array}$ \\
\hline $\begin{array}{l}\text { Approximate DFT and } 1^{\text {rst }} \\
\text { moment computer }\end{array}$ & $\mathrm{L}_{D F T}$ & $\frac{\text { series recording o }}{\begin{array}{c}\text { Quantization (2) } \\
\text { noise }\end{array}}$ & $\begin{array}{l}\text { output at this point } \\
\text { After computer simulation } \\
\text { (see } \S \text { III.2) }\end{array}$ \\
\hline
\end{tabular}

(1) already accounted in $G_{\text {IF }}$ parameter (all IF insertion losses)

(2) quantization noise accounted for in the computer simulation of the approximate DFT and 1rst moment computer.

(3) All symbols contained in that rubric design gains. However, in order to remind to the reader the exact nature of the components (amplifiers or attenuators), gains greater than unity are marked $G_{x x}$, and gains lower than unity $L_{x x}$. 
Table $2-1 / 2$

\begin{tabular}{|c|c|c|c|c|c|}
\hline \multicolumn{6}{|c|}{$\begin{array}{l}\text { Calibration data sheet } \quad \text { Radar } 2 \\
\qquad f=5630 \mathrm{MHz} / \text { Direct polarization }\end{array}$} \\
\hline $\begin{array}{c}\text { Type of calibrated } \\
\text { source }\end{array}$ & $\begin{array}{l}\text { Input } \\
\text { power } \\
\text { (1) }(\mathrm{dBm})\end{array}$ & $\begin{array}{l}\mathrm{AGC} \\
\text { attenuation } \\
(\mathrm{dB})\end{array}$ & $\begin{array}{l}\text { Measured } \\
1 \text { rst moment } \\
(3) \quad(d B)\end{array}$ & $\begin{array}{l}\text { Radar } \\
\text { noise } \\
(1) \quad(\mathrm{dBm})\end{array}$ & $\begin{array}{l}\text { Receiver } \\
\text { constant } \\
(\mathrm{dB})\end{array}$ \\
\hline $\begin{array}{c}\text { Internal sinusoīdal } \\
\text { source }\end{array}$ & -79.2 & 30 & 24.5 & -91.1 & 133.7 \\
\hline $\begin{array}{r}\text { Internal radar noise } \\
(2)\end{array}$ & - & $\begin{array}{r}0 \\
6 \\
12\end{array}$ & $\begin{array}{l}23.2 \\
18.2 \\
14.0\end{array}$ & $\begin{array}{l}-110.4 \\
-109.6 \\
-107.3\end{array}$ & $\begin{array}{l}133.7 \\
133.8 \\
133.3\end{array} \mid 133.6$ \\
\hline $10600^{\circ} \mathrm{K}$ noise source & $\begin{array}{l}-93.0 \\
-93.0\end{array}$ & elin & $\begin{array}{l}\text { ninated data } \\
23.3\end{array}$ & (saturated & $\begin{array}{l}\text { time series) } \\
134.3\end{array}$ \\
\hline
\end{tabular}

b

Calibration data sheet Radar 2

PRF $=1463 \mathrm{~Hz}$

$f=5630 \mathrm{MHz} /$ Direct polarization

(Range gate width : $100 \mathrm{~m}$ )

\begin{tabular}{|c|c|c|c|c|c|}
\hline $\begin{array}{c}\text { Type of calibrated } \\
\text { source }\end{array}$ & $\begin{array}{l}\text { Input } \\
\text { power } \\
(1) \quad(\mathrm{dBm})\end{array}$ & \begin{tabular}{|} 
AGC \\
attenuation \\
$(\mathrm{dB})$
\end{tabular} & $\begin{array}{l}1_{\text {Meassured }}^{\text {Ménent }} \\
\begin{array}{ll}(3) & (\mathrm{dB})\end{array}\end{array}$ & $\begin{array}{l}\text { Radar } \\
\text { noise } \\
(1) \quad(\mathrm{dBm})\end{array}$ & $\begin{array}{r}\text { Receiver } \\
\text { constant } \\
(\mathrm{dB})\end{array}$ \\
\hline $\begin{array}{c}\text { Internal sinusoĩdal } \\
\text { source }\end{array}$ & -79.2 & 30 & 15.9 & -94.1 & 125.1 \\
\hline $\begin{array}{r}\text { Internal radar noise } \\
\text { (2) }\end{array}$ & - & 0 & 12.8 & -112.6 & 125.4 \\
\hline $10600^{\circ} \mathrm{K}$ noise source & $\begin{array}{l}-96.5 \\
-96.5\end{array}$ & eli & $\begin{array}{l}\text { minated data } \\
22.4\end{array}$ & $\begin{array}{c}\text { (saturated time } \\
-\end{array}$ & $\begin{array}{c}\text { e series) } \\
124.9\end{array}$ \\
\hline
\end{tabular}


Table $2-2 / 2$

\begin{tabular}{|c|c|c|c|c|c|}
\hline \multicolumn{6}{|c|}{$\frac{\text { Calibration data sheet }}{f=5630 \mathrm{MHz} / \text { Direct polarization }}$} \\
\hline $\begin{array}{r}\text { Type of calibrated } \\
\text { source }\end{array}$ & $\begin{array}{l}\text { Input } \\
\text { power } \\
(1)(\mathrm{dBm})\end{array}$ & $\begin{array}{l}\text { AGC } \\
\text { attenuation } \\
(\mathrm{dB})\end{array}$ & $\begin{array}{l}\text { Meacsured } \\
1_{\text {moment }}^{\text {Prs }} \quad(\mathrm{dB})\end{array}$ & $\begin{array}{l}\text { Radar } \\
\text { noise } \\
(1)(d B m)\end{array}$ & $\begin{array}{l}\text { Receiver } \\
\text { constant } \\
\qquad(d B)\end{array}$ \\
\hline $\begin{array}{c}\text { Internal sinusoĩdal } \\
\text { source }\end{array}$ & -79.2 & 24 & 20.4 & -103.1 & 123.6 \\
\hline $\begin{array}{r}\text { Internal radar noise } \\
(2)\end{array}$ & - & 0 & 7.8 & -115.6 & 123.4 \\
\hline $10600^{\circ} \mathrm{K}$ noise source & -99.5 & 0 & 23.7 & - & 123.2 \\
\hline
\end{tabular}

(1) measured or estimated at the parametric amplifier input

(2) measured by clear air condition with a vertically pointing radar

(3) computed from recorded periodograms (640 samples average) 
FIGURES

Figure 1 a : RONSARD general diagram.

$b$ : equivalent diagram of RONSARD radars for transfer function calibrating.

Figure 2 : Block diagram of the RONSARD radars reduced receiving chain for calibrating purposes.

Minor interest parameters, such as range dependent (STC) attenuation, Fixed Target Canceller gain, and Amplitude and Phase memory corrective gain are ignored.

All RF and IF gains are reduced to only two parameters $L_{R F}$ and $G_{I F}$.

Ronsard receiver simplified block diagram for noise temperature computation is presented in the dashed frame : the overall noise temperature is a function of the AGC position. When the receiver gain is maximum, the temperature is close to the minimum value ( $2450^{\circ} \mathrm{K}$ ) indicationg the radar sensitivity. When large echoes are encountered, the gain decreases and the radar noise temperature increases. The effective temperature measured at the RF mixer input is then limited to the $\theta_{M}+\theta_{0}$ value.

Figure 3: Effective noise temperature (and associated Noise Figure) at the input of the feed horn.

Curve (a) displays the rapid variation of the effective noise temperature $\theta$ of the radar when the AGC attenuation grows up (i.e. when echo returns intensity increases).

The corresponding noise figure $F$ (curve $b$ ) is a linear function of the AGC attenuation above $18 \mathrm{~dB}$. The radar noise is then only due to the RF mixer noise magnified by the AGC attenuation of the preceding stages. 
Figure 4 : RONSARD Fourier Processor loss vs normalized input power (i.e. input power to the maximum input power ratio).

Region II is the $9 \mathrm{~dB}$ standard range of data after compression by the AGC. The increased losses in region I and III are due to quantizations influence (low level input powers) and to clamping effects (high level input powers).

Curves a to e correspond to increasing values of the PSD standard deviation represented by the normalized width parameter $2 \sigma_{S} T_{S}$.

Table 1 : Summarized behavior of all transmitter, receiver and processor radar components.

Table 2 : Calibration results obtained on RONSARD radar $\# 2$ for each of the three range gate widths. Three types of calibrated sources (RF sine wave, radar noise and RF noise source) are injected at the radar input and yield to independant measurements of the mean internal radar constant.

The different mean values obtained in the three modes result in different adjustments of the pre-integrators constants. However the large value of the constant in case (a) will be decreased by a factor $10 \mathrm{~dB}$ for a more realistic adjustement. 
ACKNOWLEDGMENTS

We are much indebted to $I$. Revah for his constant and very efficient support and to our colleagues of the CRPE, MM. Carpentier, Etcheto, Faroux and Sauvaget who provided an expert technical assistance.

The dual radar system of the CRPE has been conceived by the Centre National d'Etudes des Télécommunications (CNET) and built by the Laboratoire Central de Télécommunications with financial support of the Délégation Générale a la Recherche Scientifique et Technique, of the CNET, and of the Institut National d'Astronomie et de Géophysique. 


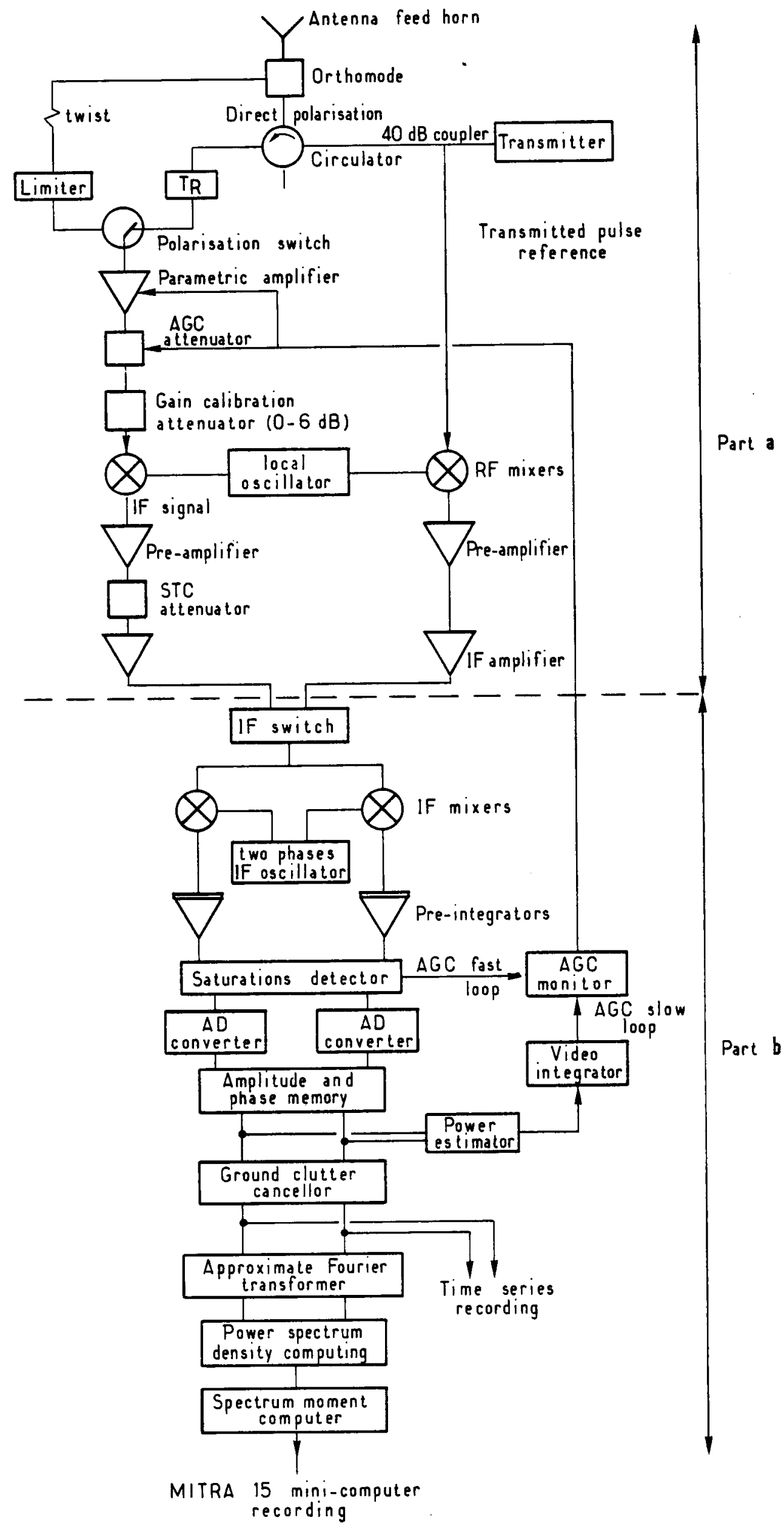




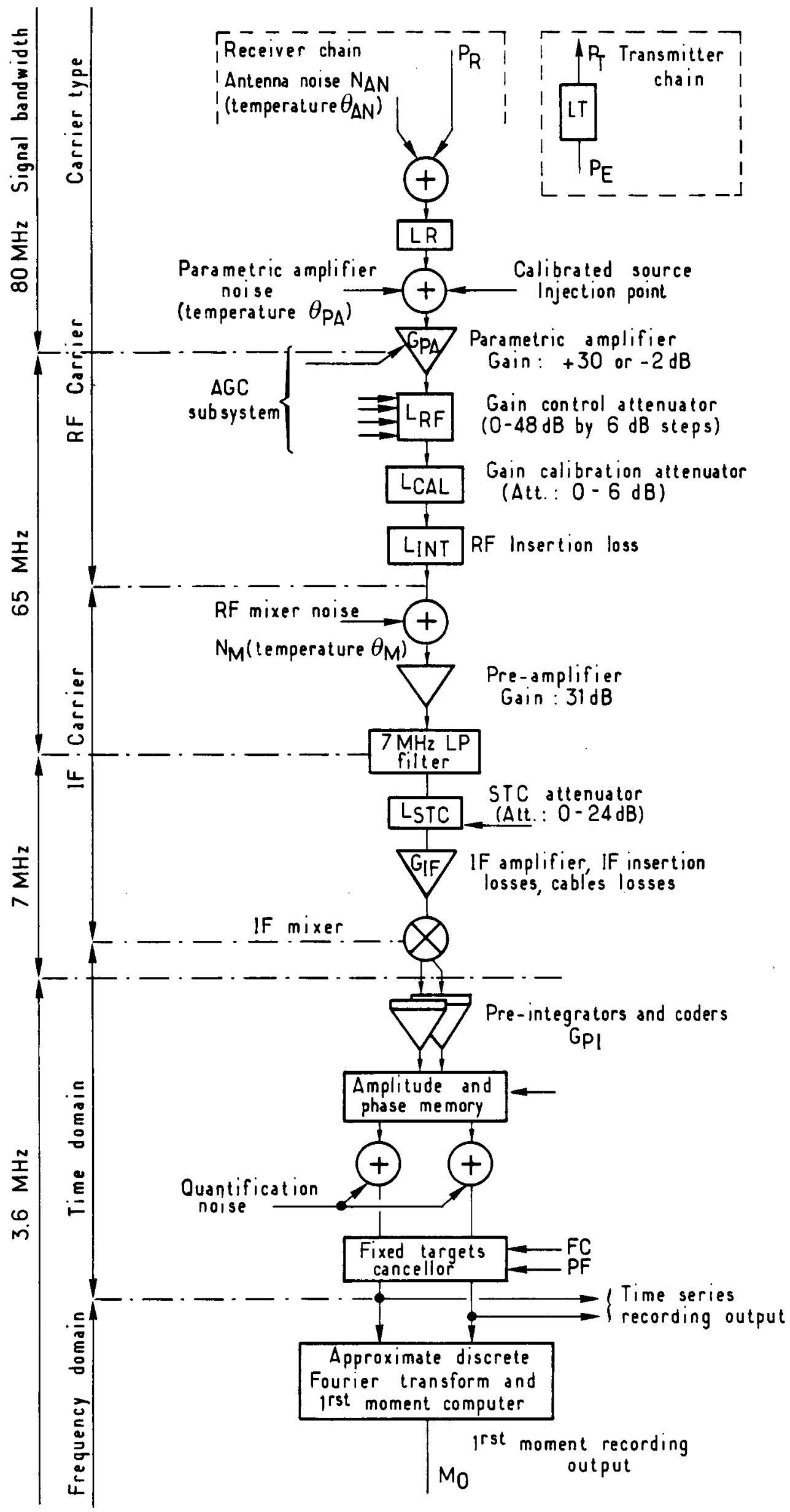




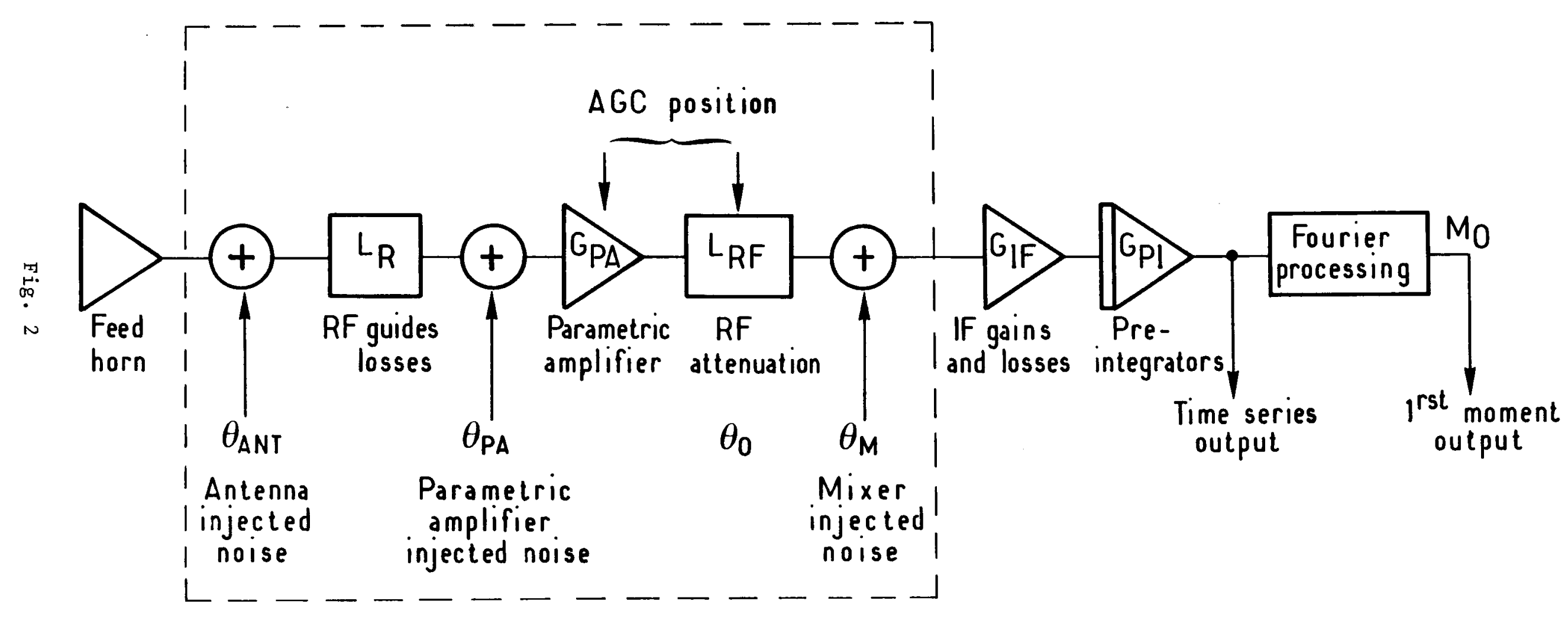




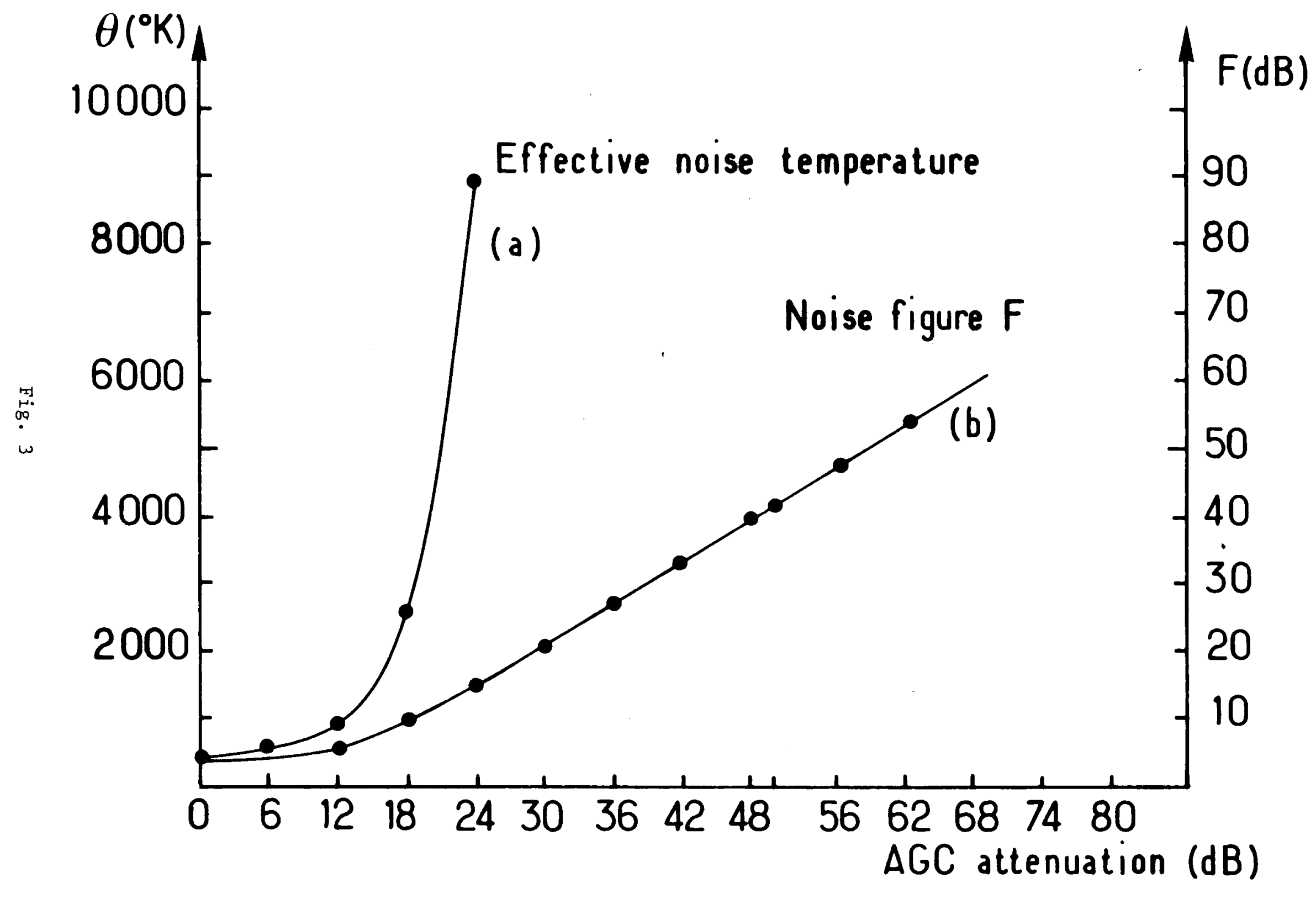




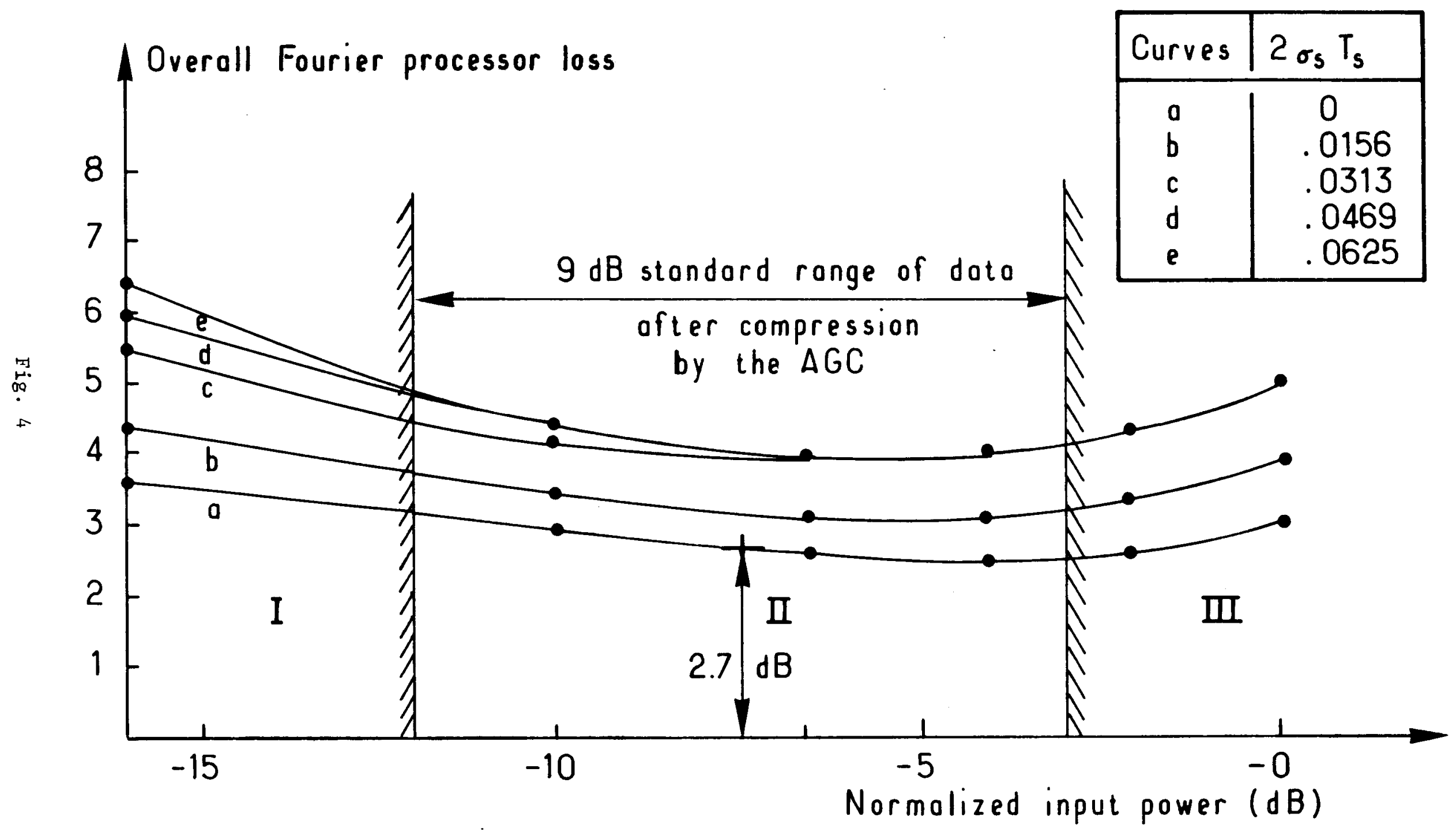


Centre de Recherches en Physique de l'Environnement terrestre et planétaire

Avenue de la Recherche scientifique 45045 ORLEANS CEDEX
Département :DCE

Physique et Chimie de l'Environnement

Avenue de la Recherche scientifique 45045 ORLEANS CEDEX
Département ETE

Etudes par Télédétection de l'Environnement

CNET - 38-40 rue du général Leclerc 92131 ISSY-LES-MOULINEAUX 